\title{
THE CLINICAL VALUE OF CHEST LEADS
}

\author{
September 10, 1947, afternoon. Section of Cardiology \\ By Frank N. Wilson, * Ann Arbor, Michigan
}

In the growth of electrocardiography as a clinical method, British physiologists and physicians have played a more important role than those of any other nationality. Waller was the first to show that the electrical activities of the human heart could be recorded by leading from the extremities or from the surface of the chest. Mackenzie, although he did not deal directly with this subject, tremendously increased our knowledge of clinical disorders of the rate and rhythm of the heart beat and aroused a world-wide interest in this field. Thomas Lewis contributed more than any other man to the development of the principles and methods of analysis upon which the interpretation of the electrocardiogram is founded. Most of my own electrocardiographic studies have been the result of ideas derived from his investigations, and I am also deeply indebted to him for help and encouragement on many occasions. I consider it a very great honour to be asked to discuss an important aspect of clinical electrocardiography here in his native land and in this great city where his work was done. It would have been a still greater pleasure to come here if he were still living and could take part in this discussion.

It was the work of Lewis and Rothschild on the spread of the excitatory process that first aroused my interest in the possibility of exploring the anterior ventricular surface by placing one electrode on the præcordium and the other far from the heart. The observations and ideas contained in their paper and notions derived from a study of the physical principles upon which the work of Einthoven and that of Waller on the electrical axis of the heart is clearly founded led to a series of investigations concerned with the character of the heart's electrical field. These investigations were first undertaken late in 1919 and were continued off and on through the early twenties. A preliminary report to the effect that præcordial leads of the kind mentioned are semi-direct leads very similar to the unipolar direct leads first used by Lewis and Rothschild was published in 1926, but the systematic use of multiple leads of this sort at the University of Michigan dates from the summer of 1929 . It was precipitated at that time by the observations on bundle branch block by Barker, Macleod, and Alexander, and was undertaken with the purpose of obtaining additional data bearing on their conclusions. A preliminary report of this work was published in 1930; the final report came out in 1932, and was nearly simultaneous with the paper on the use of a single chest lead in the diagnosis of infarction by Wolferth and Wood. Since that time the percentage of cases in which præcordial leads are employed has steadily increased. We have never taken præcordial leads routinely.

For the purpose of studying disturbances of the rate and rhythm of the heart beat, or of the time relations and sequence of auricular and ventricular activation, unipolar chest leads are only occasionally better than limb leads, and are not in general superior to bipolar chest leads of the kind used by Lewis in his studies of auricular fibrillation, and are much less useful than esophageal leads. They have not thus far proved to have any special advantages in the study of the form of the auricular complex. On the other hand, chest leads and particularly unipolar leads from the præcordium, are indispensable for the detection and differentiation of abnormalities of the ventricular complex. They frequently disclose abnormalities of the QRS group, the $T$ complex, or both, when the limb leads show either no deviation from the normal or none that have diagnostic significance. On this occasion, it will suffice to consider only those conditions in which the value of unipolar præcordial leads has been most clearly demonstrated. It should, of course, be clearly understood that clinical diagnosis should seldom, if ever, be made on the basis of electrocardiographic findings alone. To rely solely upon an interpretation of the electrocardiogram that is not supported by the case history or other clinical data after an adequate investigation has been made frequently means to run the risk of converting an essentially normal person into a psychoneurotic invalid.

Præcordial leads are of value, first of all, in the recognition of abnormalities affecting the intraventricular conduction of the cardiac impulse. They make it possible in the vast majority of the cases in which the QRS interval measures 0.12 second or more to ascertain whether one is dealing with right bundle branch block, left bundle branch block, arborization block, Wolff-Parkinson-White

* Working under a grant from the Kresge Foundation, University of Michigan. 
syndrome, or a conduction defect not belonging in any of these catagories. Intraventricular conduction defects that produce a less striking increase in the QRS interval are somewhat more difficult to differentiate, but præcordial leads often disclose the presence of incomplete right branch block when the ventricular complexes of the limb leads are not distinctly abnormal. They also make it possible in many instances to recognize such combinations as complete or incomplete right branch block plus right ventricular hypertrophy or myocardial infarction, and left bundle branch block plus left ventricular hypertrophy. The electrocardiographic diagnosis of left bundle branch block plus infarction is in our experience rarely possible. Incomplete left branch block is difficult to distinguish from the effects of preponderant hypertrophy of the left ventricle. Many have expressed the opinion that all defects in intraventricular conduction have the same clinical significance and that it is not worth while to attempt to differentiate one from another. The answer to this objection is that we cannot tell whether it is valid until the differentiation in question can be made with reasonable certainty. In the past this has not been possible, and the older studies of the significance of the different varieties of intraventricular block which were based on limb leads can no longer be considered definitive. There are some clinical disorders that produce one type of intraventricular block exclusively or much more often than any of the others. Right bundle branch block is common in pulmonary embolism, Chagas disease, infarction of the ventricular septum, and congenital cardiac anomalies in which the septum is defective; left branch block does not occur at all in some of these conditions and is rare in others. True arborization block is usually, if not always, a consequence of old infarction.

In the second place, præcordial leads are of very great value in the diagnosis of preponderant hypertrophy or enlargement of one ventricle, and particularly in the diagnosis of preponderant hypertrophy or enlargement of the right ventricle. The last is not infrequently induced by pulmonary hypertension, which is often difficult to detect by clinical means. The systematic electrocardiographic study of all cases of heart disease of obscure origin will disclose many cases of unsuspected cor pulmonale. Many patients with congenital heart disease are now candidates for cardiovascular surgery. The use of præcordial leads in such cases frequently yields valuable evidence bearing on the presence or absence of suspected or unsuspected complications. It is now clear that the position of the mean electrical axis of the QRS deflections is determined not by the relative weight or size of the two ventricles, but by the position of the heart in the chest. This is not wholly determined by the nature of the cardiac lesion present. Thus it is possible to have right axis deviation in a case of preponderant enlargement of the left ventricle or left axis deviation associated with preponderant enlargement of the right ventricle.

Finally, chest leads find their greatest field of usefulness in the diagnosis of myocardial infarction, and I have seen a great many instances in which this condition was certainly present and not recognizable by any other method. There are a great many infarcts of the less extensive sort that can be easily recognized if præcordial leads are taken, and nevertheless give rise to no constitutional symptoms whatsoever and to only the most trivial complaints. The infarcts that are least likely to produce characteristic changes in the limb leads but regularly give rise to such changes in præcordial leads are those that involve the anterior part of the ventricular septum and adjacent parts of the anterior wall of the left ventricle. We speak of these as anteroseptal infarcts. Other types of infarcts that produce more striking changes in præcordial leads than in the limb leads are those associated with right bundle branch block, which usually involve the upper ventricular septum, those that for some reason give rise to small bizarre deflections in all of the standard limb leads, and certain posterior or high lateral infarcts. It is desirable to take præcordial leads in all cases in which myocardial infarction is considered a possibility and in all cases in which symptoms of cardiac weakness or cardiac failure develop rapidly without obvious cause. If this is done many instances of clinically undiagnosed examples of infarction will be discovered.

In considering abnormalities of the form of the ventricular complex, particularly those of a nonspecific kind, it is necessary to ask one's self whether they are the result of (1) a minor congenital anomaly, (2) some long past illness which has left behind an anatomic or physiologic scar, (3) an acute process, such as acute myocarditis, myocardial infarction, pericarditis, or toxæmia, or (4) a slowly progressive degenerative condition such as coronary atherosclerosis. Perhaps a fifth possibility, derangement of the vegetative nervous system should be added. In reaching a decision it is often necessary to repeat the electrocardiographic examination at intervals over a considerable period. If the electrocardiographic changes persist unchanged, they should not be ascribed to an acute process. It is also imperative that the final conclusions be based on a careful scrutiny of all the clinical and laboratory data available, and not upon the electrocardiogram alone. 


\author{
By C. W. Curtis BaIN \\ This communication has been published in fuller form (Brit. Heart J., 1948, 10, 9).
}

\title{
By Terence East
}

After hearing Dr. Wilson's address and studying his writings, it is clear that unipolar leads can afford valuable information, more clear than any hitherto available. The difficulty is that the full electrical exploration of the heart may involve the taking of so many records. If one uses the three standard, the six unipolar chest, with perhaps an abdominal or epigastric, the three unipolar limb leads and, possibly, other thoracic and an œsophageal lead, one may end by taking some fifteen or sixteen tracings. For ordinary clinical practice this is too many; time does not permit such elaboration; one must now begin to consider whether a new approach may not be adopted which will reduce the initial number of leads used: further exploration can be done to elucidate details, but it might be possible to cut down the number taken at first; or perhaps select special leads suitable for obtaining special information. This seems more logical than just using the standard leads and one or more præcordial leads at random. This method must surely become obsolete in the near future.

Definite information can be sought from the cardiogram on the following points. The answer is often final and conclusive.

1. Auricular activity. This is essential in the interpretation of most of the arrhythmias, especially circus movements, and in the study of auriculo-ventricular conduction.

2. Intraventricular conduction and bundle branch block.

3. Indication of unilateral or bilateral ventricular hypertrophy and strain.

4. The position of the heart.

5. Pathological changes in the myocardium; in particular ischæmic disease, and the detection and localization of infarcts; and also unspecific minor variations from the normal.

6. Pulmonary embolism and infarction. This might come under heading 3.

7. Pericarditis, with or without effusion.

To a certain degree the three standard leads have for long revealed a good deal on these points; the addition of chest leads was the first extension into further fields of exploration. The choice of chest contacts is wide; both in site of application; and also whether a unipolar or paired technique should be used. It would appear that there are good reasons for employing the unipolar præcordial technique rather than using a distal electrode on the right arm or left leg. There are also good reasons for using unipolar limb leads, rather than the standard, for thereby true single changes of potential are recorded rather than the differences between two. Apart from the six præcordial contacts, running from right to left, there are others that have been proposed. One of the most promising was the right upper abdominal, which, by a high positive deflection, might be useful as an indication of hypertrophy of the right ventricle. This is not the case, for it has been found that such deflections are given in this lead by vertical hearts, which are actually normal. One might suggest that a practical solution of the difficulties arising from the taking of so many leads is to select the following, for the reasons that are appended.

Lead V 1.

1. This will show auricular waves, and be useful for circus movements, auricular tachycardia, and for measuring auriculo-ventricular block.

2. A large $\mathrm{R}$ and small $\mathrm{S}$ will show right ventricular hypertrophy.

3. The position of the intrinsic deflection in a prolonged QRS will diagnose the site of bundle branch block.

4. The size of the normally negative deflection will show the position of the heart.

Lead V 4 (or V 5). The one selected depends on the size of the heart; it should be just outside the apex beat. (V 6 or 7 might on occasion be needed.)

1. Hypertrophy of the left ventricle is shown by the large $R$ and no $S$ wave. $T$ may be negative (as in standard lead I). Digitalis effects are shown.

2. Anterior infarcts are shown by $Q$ and changes in RS-T junction and $\mathrm{T}$ waves.

3. Bundle branch block location is confirmed by the position of the intrinsic deflection in a prolonged QRS.

4. Possibly changes due to pericarditis.

Lead VL. (The unipolar left arm lead.)

1. This may reveal some lateral infarcts.

2. The position of the heart is shown, particularly when vertical, the normally positive leads becoming small or negative.

3. One might expect changes due to pericarditis.

Lead VF. (The unipolar left leg lead.)

1. Posterior infarcts are shown.

2. The changes of pulmonary infarction are detected. 
3. The position of the heart is shown, particularly when horizontal.

4. One might expect changes due to pericarditis. By giving the third strip on the film two separate exposures V L and V F can be shown consecutively, and all four leads will then appear on one film. It is intended to adopt this selective technique on a series of cases, controlled by the standard leads, to determine whether the latter can ultimately be dropped altogether. It may at any time be desirable to amplify the preliminary data obtained by such an approach with full electrical exploration of the heart, using such additional leads as may seem indicated.

\section{By Camille Liàn, Paris}

After the very interesting communication of Dr. Wilson and Dr. Bain, I shall only say a few words about two chest leads that I have specially studied.

First, the auricular lead which I have named S 5; the right arm electrode is placed on the middle of the sternal manubrium and the left arm electrode on the anterior extremity of the fifth right intercostal space. In this way, the auricular waves are well recorded even when they are invisible in the limb leads. For the same purpose, I have recently employed with success the well known chest leads CF 1 and V 1, but the chest lead S 5 gives better results.

For another purpose, I have used the chest lead BF (back-foot) or VB (back-central terminal - of Wilson). After placing the exploring electrode in the standard position, 1, 2, 3, 4, etc., I place it mid- way between the left scapula and the spine, two fingers above the inferior angle of the scapula. In this lead, the $T$ wave is negative in healthy subjects.

As you know, in cases of coronary disease giving the T III type of curve in limb leads, the $T$ wave generally keeps its normal direction in standard chest leads. But these same cases generally show a reversal of $T$ wave in the chest lead BF or V.B, taken as described; that is to say the normally negative $T$ wave becomes positive.

Therefore, in a case presenting an inverted $\mathrm{T}$ in lead III, this special chest lead may be informative, for if the inverted T III is due to coronary occlusion, the chest lead BF generally shows a reversal of $T$, that is a positive instead of a negative $T$ wave. The chest lead BF of VB can thus be useful in cases presenting the T III type of electrocardiogram. 